\title{
Trajetória e perspectivas da gestão privada do saneamento na América Latina: contrastes e aproximações entre Brasil e Argentina
}

\section{Path Dependence and Prospects of Private Provision of Water and Sanitation Services in Latin America: Contrasts and Convergences between Brazil and Argentina}

\author{
Marcelo Coutinho VARGAS* \\ Bernard de GOUVELLO**
}

\begin{abstract}
RESUMO
Com base na literatura especializada e na pesquisa de algumas fontes primárias, o texto examina os contrastes e as aproximações na trajetória das políticas de saneamento pró-mercado implantadas no Brasil e na Argentina durante os anos 1990, procurando entender como políticas semelhantes, adotadas em conjunturas similares, tiveram alcance e resultados tão diversos, à luz das noções de "capital social" e "dependência da trajetória". Procura examinar igualmente as perspectivas atuais de desenvolvimento da gestão privada dos serviços deste setor em ambos os países.
\end{abstract}

Palavras-chave: políticas de saneamento pró-mercado; Brasil e Argentina; contrastes e aproximações; dependência da trajetória; perspectivas da gestão privada.

\begin{abstract}
This paper analyzes how and why practically the same pro-market water and sanitation policies adopted by Argentina and Brazil during the 1990s have attained contrasting results and impact in each country. It argues that those differences may be largely explained by the notions of "path dependence" and "social capital" related to historical policy choices made in this field at the national level.
\end{abstract}

Key-words: pro-market water and sanitation policies; Argentina and Brazil; contrasting results and impacts; path dependence; private provision prospects

\footnotetext{
* PhD em Urbanismo pela Universidade de Paris XII. Professor do Programa de Pós-Graduação em Ciência Política e do Depto. de Ciências Sociais da UFSCar. Email: vargasm63@gmail.com

${ }^{* *}$ Doutor em Urbanismo pela Universidade de Paris XII. Professor da Universidade de Paris Leste. Pesquisador do Centre de Recherches sur l'Eau, la Ville et l'Environnement (CEREVE) da École Nationale des Ponts et Chaussées (ENPC). Email: bernard.degouvello@cereve.enpc.fr
} 


\section{Introdução}

No início dos anos 1990, em sintonia com as políticas de ajustamento estrutural impostas pelo Fundo Monetário Internacional aos países em desenvolvimento, cujas economias se encontravam arruinadas pela dívida externa e pela inflação, o Banco Mundial passa a promover modelos de gestão do saneamento baseados no crescente envolvimento do capital e da empresa privada como estratégia privilegiada para obter ganhos de eficiência, melhorar a qualidade e expandir o acesso da população aos serviços. Tal orientação foi logo seguida por outras agências internacionais, a exemplo do Banco Interamericano de Desenvolvimento (BID). Para ter acesso ao crédito internacional destinado ao setor, com taxas de juros reduzidas, tais países teriam de cumprir as exigências desta política, i.e.: promover mudanças político-institucionais que favorecessem a transferência da gestão dos serviços urbanos de abastecimento de água potável e/ ou esgotamento sanitário a companhias privadas transnacionais, preferencialmente via contratos de concessão. $\mathrm{O}$ aporte de novos investimentos e a transferência de tecnologia de ponta ao setor eram os principais benefícios esperados das políticas de saneamento pró-mercado, que tiveram na América Latina sua área de atuação privilegiada (CASTRO, 2005; FOSTER, 2005; SEPPÄLA, 2003).

Geralmente pouco animadores, quando não decepcionantes, os resultados de tais políticas também se revelaram muito diferenciados nos dois países mais poderosos da América do Sul. Na Argentina, onde estivera ausente do saneamento até então, a "gestão privada" aparece no início dos anos 1990 e se difunde amplamente em poucos anos, sob a forma de inúmeros contratos de concessão, envolvendo diferentes níveis de governo e escalas territoriais ${ }^{1}$. Foram firmados contratos não apenas com os municípios, mas também com as províncias e o governo nacional. Em menos de 10 anos, a gestão dos serviços por concessionários privados se torna predominante, chegando a atender aproximadamente $60 \%$ da população urbana argentina com acesso à água encanada (FOSTER, 2005). Porém, quase todos os contratos serão prematuramente rompidos, sobretudo após a crise de 2001, levando a um drástico declínio da gestão privada deste setor no país desde então.
No Brasil, onde o processo de privatização foi desencadeado um pouco mais tarde, no início de 1995 , com a aprovação da lei federal $n^{\circ} 8.987$, a chamada Lei de Concessões, a expansão da gestão privada vem se dando lentamente neste setor, permanecendo ainda hoje ligeiramente inferior a $10 \%$ da população urbana com acesso à água encanada. Quase todos os contratos de concessão em vigor concernem à esfera local, tendo sido firmados com as respectivas prefeituras (muitas vezes com interferência ativa dos governos estaduais). Além disso, apesar da situação litigiosa que envolveu numerosos contratos no início do processo (alguns permanecem sub judice) e a despeito da maior parte das companhias transnacionais envolvidas terem deixado o país, vendendo sua participação nas empresas brasileiras do setor, até o momento não se tem notícia de nenhum contrato que tenha sido rompido antes do seu termo.

Como explicar estas diferenças na trajetória da gestão privada do saneamento nos dois países examinados? Podemos imputá-las a mecanismos internos, peculiares a cada nação, tendentes a favorecer ou dificultar a adoção de políticas pró-mercado neste setor? As reformas que foram colocadas em prática refletiram a adoção de um mesmo modelo exógeno de gestão privada ou, ao contrário, apresentaram algum grau de adaptação do receituário pró-mercado ao contexto setorial e político-institucional específico de cada país? Por fim, será que, para além das diferenças constatadas, é possível observar alguma convergência entre a Argentina e o Brasil no que se refere ao legado e ao futuro da gestão privada do saneamento?

Tendo por objetivo responder às questões acima, o presente artigo se divide em três seções, seguidas de uma breve conclusão. Na primeira, após uma sucinta revisão crítica da literatura que analisa a "era neoliberal" de promoção das políticas pró-mercado no saneamento urbano dos países em desenvolvimento, América Latina em particular, apresentamos as noções neoinstitucionalistas de "trajetória" e "dependência da trajetória", mobilizadas em nosso esforço de análise comparativa. Na seção seguinte, a noção de trajetória é utilizada para descrever o processo de desenvolvimento de tais políticas na Argentina e no Brasil. Na terceira seção, a noção de "dependência da trajetória" é empregada, de um lado, para demonstrar o peso estruturante de antigas políticas nacionais na configuração atual do setor

\footnotetext{
${ }^{1}$ A noção de "gestão privada" adotada aqui se refere exclusivamente à situação em que um operador privado assume a responsabilidade direta pela prestação dos serviços de saneamento aos usuários, mediante delegação legalmente autorizada do poder público. O uso desta noção, no lugar de "privatização", permite-nos contornar confusões ideológicas decorrentes da utilização abusiva do último, que costuma simplificar o debate das políticas pró-mercado.
} 
em cada país e, de outro, para explicar as principais tendências convergentes e divergentes observadas neste campo entre os dois países ao longo do período estudado. Por fim, diante das análises precedentes, e à guisa de conclusão, buscamos fazer uma breve avaliação das perspectivas atuais da gestão privada em ambos os países.

\section{Por uma nova abordagem da gestão privada da água e do saneamento nos países em desenvolvimento}

\section{Uma crítica do debate recente}

A rápida difusão das políticas de saneamento pró-mercado nos países em desenvolvimento ao longo dos anos 1990, e seu declínio posterior, já foram objeto de numerosas avaliações, pesquisas e debates (BOTTON, 2007; DUCCI, 2007; LOBINA; HALL, 2007; CASTRO, 2005; FOSTER, 2005; GUASCH, 2004). Esta literatura mostrou os limites dos modelos internacionais da gestão privada, tendo contribuído para explicar o malogro de diversos contratos envolvendo os serviços de abastecimento de água e esgotamento sanitário de grandes cidades no hemisfério sul. Porém, esta bibliografia apresenta sérias limitações no que tange à excessiva simplificação do quadro de análise predominante, além do caráter restrito dos estudos de caso em que baseia suas conclusões.

Em primeiro lugar, a maior parte das avaliações das políticas de saneamento pró-mercado deste período concentrou sua análise em um número reduzido (geralmente os mesmos) de experiências, sempre envolvendo contratos de concessão de grande envergadura disputados no mercado internacional, especialmente os que foram prematuramente rompidos na América Latina (Buenos Aires, Tucumán, Cochabamba, La Paz-El Alto) ou drasticamente revisados para baixo no Sudeste da Ásia (Jacarta, Manila). Aliás, estudos dos mesmos casos dão origem a análises bem distintas: os autores que se opõem sistematicamente às políticas pró-mercado no âmbito da água e do saneamento tendem a ver nestes casos a prova das limitações inerentes a tais políticas nos países em desenvolvimento (LOBINA; HALL, 2007; CASTRO 2005), ao passo que os defensores procuram explicar o fracasso dessas grandes concessões pela intervenção de "fatores externos" independentes do arranjo adotado (DUCCI, 2007; FOSTER, 2005; GUASCH,
2004). Raros são os trabalhos cujas análises não se baseiam em avaliações aprioristicamente favoráveis ou contrárias à "privatização" do setor (nas diversas modalidades possíveis), originando avaliações menos ideológicas e mais isentas das mesmas concessões (MAYAUX, 2008; BREUIL, 2004; SCHNEIER; GOUVELLO, 2003), ou, ainda, que se debruçam sobre casos menos emblemáticos, com resultados ambivalentes ou parcialmente favoráveis, como se observa em algumas concessões municipais do Brasil (ROBLES; VIGNOLI et. al., 2008; VARGAS, 2005). Igualmente raros são os trabalhos focalizados em experiências que fogem ao modelo ortodoxo das grandes concessões para examinar outros arranjos, tais como a "privatização à inglesa" ocorrida no Chile (DUPRÉ-ECHEVERRIA, 2003; GÓMEZ-LOBO; VARGAS, 2002) ou as diversas modalidades de "parceria público-privada" desenvolvidas na África (JAGLIN, 2005). Mais raros, ainda, são os trabalhos que buscam analisar os desdobramentos da reestatização dos serviços concedidos à iniciativa privada (COING, 2006).

Enfim, tendo centrado o debate na questão da "privatização", a maior parte da literatura tende a negligenciar a análise de outras mudanças institucionais promovidas neste campo nos países em questão durante o mesmo período, tais como a descentralização e a regionalização da prestação de serviços, a implantação de dispositivos jurídico-administrativos de regulação, a abertura de novos canais de participação aos usuários, ou, ainda, a implantação de políticas de gestão dos recursos hídricos.

Isto nos conduz diretamente à segunda deficiência principal desta literatura, a simplificação excessiva do quadro de análise predominante na maioria dos trabalhos. Tal simplificação se traduz na categorização grosseira dos "modelos" de gestão privada difundidos pelas agências multilaterais e seu impacto sobre o setor nos países que os adotam. Os trabalhos que pretendem fazer um balanço das experiências de privatização neste setor referem-se amiúde a dois modelos de gestão privada dos serviços que se encontrariam em concorrência no mercado internacional: por um lado, a privatização "à inglesa", caracterizada por permitir a venda da infraestrutura e dos ativos públicos a companhias privadas e deixar a regulação das tarifas e da qualidade dos serviços a cargo de organismos especializados, com ampla autonomia administrativa e financeira e independência decisória em relação aos governos; por outro, a privatização "à francesa", que se baseia na delegação da prestação dos serviços a operadores privados, sob diversas modalidades de contrato, mantendo em todos os casos a propriedade 
pública dos ativos e a regulação a cargo da autoridade responsável (geralmente o poder público municipal). Ora, mesmo que se reconheça que elementos de ambos os modelos estão se mesclando de maneira original nos países do sul, notadamente na América Latina (FOSTER, 2005), esta abordagem superestima o poder explicativo destes modelos. A maioria dos autores entende as reformas neoliberais deste período como uma espécie de enxerto de modelos exógenos nas instituições locais, o que os conduz a desconsiderar que todas as políticas pró-mercado tiveram de enfrentar a oposição mais ou menos organizada de diversos atores sociais, bem como se adaptar ao ambiente institucional e à conjuntura política e econômica de cada país. Enfim, a falta de perspectiva histórica e sociológica desta literatura lhe impede de analisar os laços que unem o passado ao presente do setor, dificultando uma avaliação mais acurada das perspectivas de evolução do mesmo, particularmente no que tange à participação do capital e da iniciativa privada na prestação dos serviços.

São estas as principais limitações da literatura internacional dedicada ao tema em questão que pretendemos contribuir para superar neste trabalho, partindo de uma análise comparativa das políticas de saneamento pró-mercado adotadas paralelamente na Argentina e no Brasil, durante os anos 1990, quando as ideias neoliberais predominavam na política econômica de praticamente todos os países da região. Naquele momento, a reabilitação do dogma do "estado mínimo" se traduzia no então chamado Consenso de Washington (estabilidade monetária, redução dos gastos e controle das contas públicas, liberalização comercial e financeira, desregulamentação e desestatização da economia etc.), promovido sob a batuta do FMI e do Banco Mundial.

\section{Instituições e mudança institucional: elementos para um novo quadro de análise}

Para explicar os resultados distintos e a evolução diferenciada da gestão privada do saneamento nos dois países, buscamos alguns elementos de análise nas reflexões da nova economia institucional. De acordo com esta escola de pensamento, mesmo que os governos disponham de ampla margem de manobra para formular, implementar e ajustar as diferentes políticas públicas, nenhuma delas pode ser concebida como a mera aplicação de um modelo exógeno, dotado de características totalmente independentes do contexto socioeconômico e político-institucional do país en- volvido. Ao contrário, o reconhecimento e a mobilização do capital social presente nas instituições formais e informais das coletividades territoriais seriam condição necessária ao sucesso de qualquer política setorial (PUTNAM, 1993). Mas, qual é a natureza das instituições? Qual o significado da noção de capital social?

Sob o prisma da sociologia, as instituições são regras duráveis de ação coletiva sancionadas pela sociedade, que repousam sobre forte consenso historicamente construído sob condições socioculturais particulares. Sendo assim, não são e não podem ser facilmente transferidas de uma sociedade para outra. Para a economia institucional, trata-se de regras coletivas de comportamento, formais ou informais (leis, contratos, códigos de conduta), que regulam a interação e impõem limites às escolhas dos agentes socioeconômicos. Contribuem para reduzir os custos de transação e constituem fonte de incentivos aos quais os indivíduos e organizações costumam reagir de maneira relativamente previsível, de acordo com a noção de "racionalidade limitada". Nessa perspectiva, é preciso distinguir as regras das organizações públicas e privadas que as aplicam. De acordo com North (1990), estas últimas fazem parte do ambiente institucional, que contribuem para modificar ao perseguirem seus próprios objetivos, mas não constituem, elas mesmas, instituições.

O conceito de capital social, concebido por Putnam (1993) como uma noção complementar à abordagem da economia institucional, explica por que certas instituições funcionam melhor que outras enquanto regras reguladoras da ação coletiva. Sugere que a eficácia das instituições é condicionada pela densidade de interação entre agentes e redes sociais que partilham raízes culturais comuns, sobre as quais se constroem relações de confiança e compromissos de longa duração. A acumulação de capital social facilita a cooperação e inibe o comportamento oportunista entre os atores de uma determinada região ou setor. Esta ancoragem histórica e cultural da concepção de capital social de Putnam aparece igualmente na noção "dependência da trajetória" (path dependence), segundo a qual as escolhas técnicas e políticas do presente são condicionadas pelos efeitos de escolhas estruturantes feitas no passado. Tais noções sugerem ser preciso sempre analisar o ambiente institucional (as regras e as organizações) que envolve as políticas públicas em vigor para avaliar adequadamente não apenas a eficácia de tais políticas, mas também os respectivos limites e possibilidades de evolução. As análises desenvolvidas inspiram-se nestas premissas. 


\section{A gestão privada dos serviços urbanos de abastecimento de água e esgotamento sanitário na Argentina e no Brasil: trajetórias contrastantes}

A adoção de políticas de saneamento pró-mercado nos dois países, ao longo dos anos 1990, ocorre numa conjuntura particular, na qual as ideias neoliberais contra a intervenção do Estado na economia dominam não apenas a cena política internacional, mas também o discurso e os programas das agências multilaterais de cooperação. Após ter constatado os resultados decepcionantes de suas políticas para a Década Internacional da Água Potável e do Saneamento (1980-1990), baseadas em investimentos massivos em grandes obras de infraestrutura associadas à gestão centralizada dos serviços por empresas públicas de caráter nacional ou regional, o Banco Mundial decide promover políticas pró-mercado (BREUIL, 2004). Endividados e submetidos a políticas de ajustamento estrutural impostas pelo FMI, os principais países da América Latina não apenas adotaram as políticas de saneamento pró-mercado, como se tornaram a principal praça mundial para o investimento privado neste setor.

Assim, de acordo com Foster (2005), entre 1990 e 1999, o conjunto das operações envolvendo a participação da iniciativa privada na prestação dos serviços urbanos de saneamento (água e esgotos) que ocorreram na América Latina conseguiu captar um total de US\$ 14,7 bilhões em investimentos privados. Este montante corresponde a cerca da metade do total investido pelo capital privado nos países em desenvolvimento durante este período neste setor. Todavia, segundo a mesma fonte, a maior parte dos investimentos foi concentrada em um grupo seleto de países, a começar pela Argentina, que recebeu mais da metade do total (54\%), seguida do Chile (22\%). O Brasil aparece em terceiro lugar (11\%), seguido do México (6\%) e da Bolívia (5\%).

\section{A trajetória da gestão privada do saneamento na Argentina}

A Argentina foi o primeiro país latino-americano a abrir caminho para o investimento privado nos serviços do setor. No plano político-institucional, a política setorial de descentralização desencadeada pelo governo nacional no início dos anos 1980 preparou o terreno para o desenvolvimento da gestão privada neste país. A infraestrutura e os serviços de abastecimento de água e esgotamento sanitário de todas as cidades argentinas, até então sob responsabilidade de uma empresa pública do governo central - Obras Sanitarias de la Nación (OSN) -, vão sendo paulatinamente transferidos aos governos provinciais e, excepcionalmente, a certos municípios, enquanto a empresa nacional se mantém na administração das redes e serviços da capital e da maior parte da região metropolitana de Buenos Aires. Alguns anos depois, a primeira concessão dos serviços deste setor à iniciativa privada ocorre, em 1991, na província de Corrientes, cujo governo concedeu por 30 anos a gestão dos serviços da capital homônima e mais nove cidades vizinhas (envolvendo cerca de 300 mil pessoas, na época) a um consórcio internacional controlado pela companhia Thames Water ${ }^{2}$.

Mas, o momento crucial da gestão privada do saneamento na Argentina acontece em 1993, quando o governo do presidente Menem (1989-1999) decide privatizar a OSN, no bojo de seu programa de reforma do Estado. Os serviços de abastecimento de água e esgotamento sanitário de Buenos Aires e outras treze cidades vizinhas, abrangendo uma população que totalizava cerca de 8,5 milhões de pessoas, na época, são concedidos por um período de 30 anos à companhia Aguas Argentinas, um consórcio internacional controlado pela multinacional francesa Suez-Lyonnaise des Eaux. Apresentado como exemplo aos países em desenvolvimento, este modelo de gestão vai difundir-se progressivamente no território argentino. Nos anos seguintes, mais de uma dezena de concessões são confiadas a consórcios privados internacionais. Geralmente conduzidas pelos governos provinciais, abrangem as cidades mais importantes do país, entre as quais se destacam: Rosário, Santa Fé, Córdoba, Mendoza, La Plata, Bahia Blanca e Tucumán (cf. Tabela 1). Também são envolvidos neste movimento os serviços das cidades da periferia distante da Grande Buenos Aires, bem como as capitais e outros centros urbanos das províncias do norte, além de serviços municipais de menor dimensão. A difusão deste modelo atinge seu apogeu no início dos anos 2000 , quando cerca de $56 \%$ da população atendida passa a depender de serviços prestados por operadores privados (AZPIAZU et al., 2008).

\footnotetext{
${ }^{2}$ Algo semelhante ocorreu no Chile, onde a gestão do setor, igualmente centralizada num organismo nacional, o SENDOS, passou por um rápido processo de descentralização em 1990, dando origem a treze empresas regionais. A partir de 1998, algumas serão privatizadas segundo um modelo em que o Estado preserva obrigatoriamente ao menos $35 \%$ das ações de seu respectivo capital.
} 
VARGAS, M. C.; GOUVELLO, B. de. Trajetória e perspectivas da gestão privada do saneamento...

TABELA 1 - PRINCIPAIS CONTRATOS DE CONCESSÃO DOS SERVIÇOS DE ABASTECIMENTO DE ÁGUA E ESGOTAMENTO SANITÁRIO À INICIATIVA PRIVADA FIRMADOS NAARGENTINA, DESDE OS ANOS 1990, POR ORDEM CRONOLÓGICA

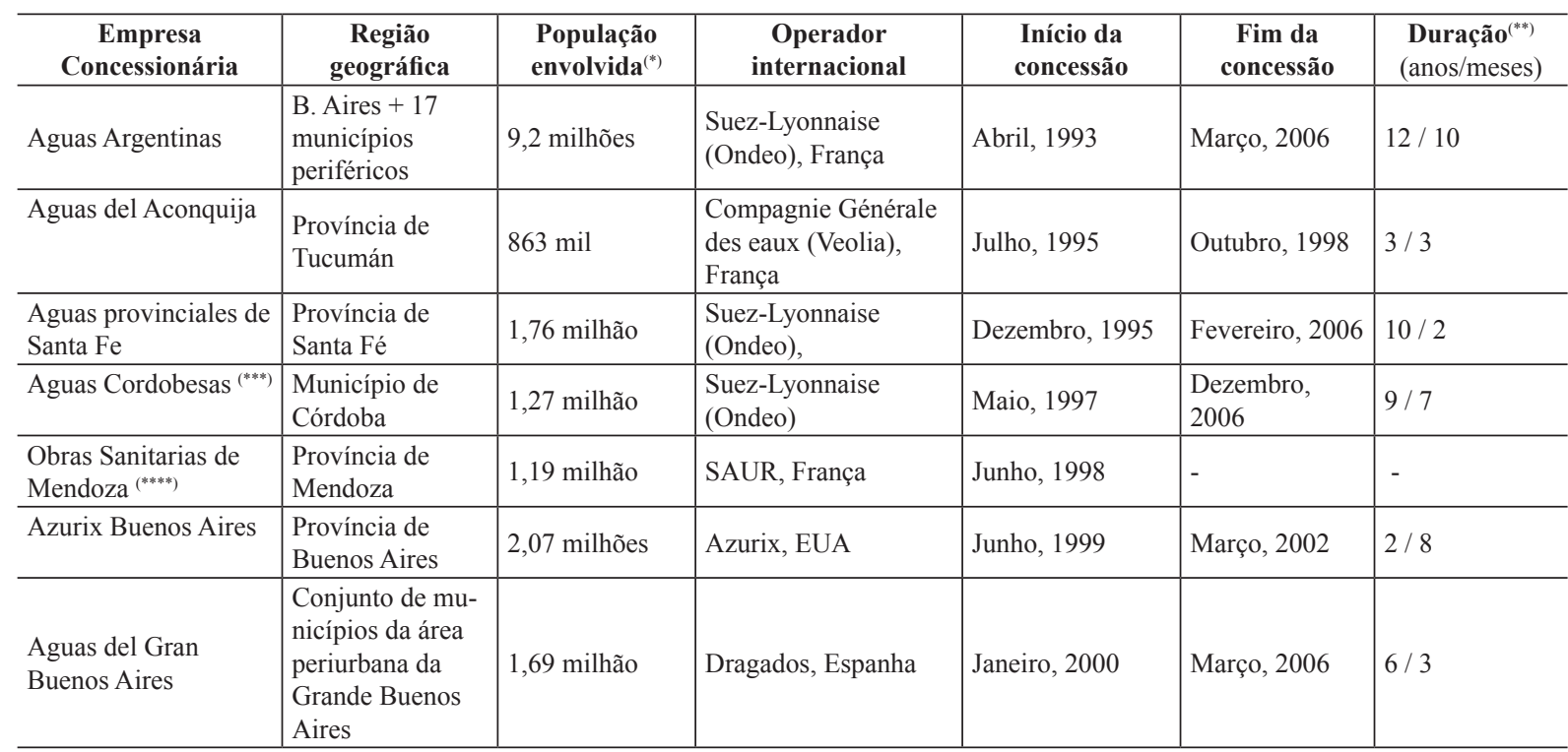

(*) População total residente na área de concessão. Dados arredondados extraídos de Azpiazu et al. (2008).

${ }^{(* *)}$ Em todos os casos, exceto Mendoza (cf. infra), a duração contratual das concessões era de 30 anos.

${ }^{(* * *)}$ Em Córdoba, somente o serviço de água foi concedido à companhia Aguas Cordobesas S.A.

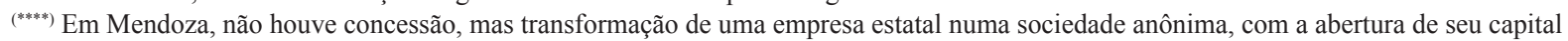
à participação de acionistas privados (AZPIAZU et al., 2008).

A primeira crise deste modelo de gestão aparece em 1997, data da rescisão do contrato de concessão da empresa Aguas del Aconquija, consórcio liderado pela multinacional francesa Compagnie Générale des Eaux (atual Veolia), na província de Tucumán. Quatro anos depois, em outubro de 2001, a empresa Azurix Buenos Aires anuncia a decisão de rescindir unilateralmente o seu contrato (confirmada no início de 2002). Em dezembro daquele ano, diante de uma profunda crise nacional, o governo central argentino decide impor uma drástica desvalorização da moeda nacional, o peso, cuja paridade com o dólar estadunidense vinha sendo garantida pela lei da convertibilidade desde 1992. Esta medida desencadeia um processo generalizado de renegociação dos contratos de concessão de serviços públicos a operadores privados, durante o qual as tarifas permanecem congeladas. Entre 2005 e 2006, as duas concessões de saneamento mais importantes do país são prematuramente encerradas com a rescisão dos contratos firmados com as companhias Aguas Argentinas e Aguas Provinciales de Santa Fe. A tendência prossegue com a interrupção dos contratos celebrados com as empresas Aguas del Gran Buenos Aires e Aguas Cordobesas, em 2006, e, posteriormente, a rescisão do contrato da firma Aguas del Valle, na província de Catamarca, em 2008.

$\mathrm{O}$ fato de quase todas as multinacionais que investiram no mercado argentino de saneamento terem deixado o país nos últimos anos (resta a SAUR, em Mendoza) representa o fim de um período no qual os consórcios internacionais estruturaram a gestão do setor neste país. Com efeito, a concessão dos serviços de saneamento de La Rioja, em 2002, foi o único contrato relevante firmado desde então. Assim, já em 2007, a gestão pública volta a predominar neste setor na Argentina, enquanto a gestão privada, cuja participação caiu para menos de $15 \%$ da população atendida, passa a depender essencialmente de companhias de capital nacional (AZPIAZU et al., 2008) ${ }^{3}$. 
Latinaguas, pertencente ao grupo Chamas, chegou a atender 1,59 milhão de habitantes com água potável e 1,11 milhão com esgotamento sanitário em concessões envolvendo 132 localidades distribuídas nas províncias de Corrientes, Salta e la Rioja. Após a rescisão do contrato de Aguas de Salta, perdeu cerca de dois terços de suas concessões.

Saguas Internacional, também denominada South Water, é uma filial do grupo Sielecki, originário de Mendoza e presente em numerosos setores de atividade na Argentina. A empresa está presente no capital da OSM (Obras Sanitarias de Mendoza), com uma participação que, desde janeiro de 2009, supera 30\% das ações da última. Em 1995, Saguas Internacional obteve a concessão dos serviços de água e esgotos das cidades de Formosa e Clorinda, na província de Formosa (Aguas de Formosa) e, dois anos depois, a concessão conjunta dos serviços de quatro cidades vizinhas na província de Santiago del Estero (Aguas de Santiago).

Consolidado inicialmente no setor da construção civil, o grupo Roggio foi um ator central na onda de privatizações dos anos 1990, notadamente na área de rodovias e telecomunicações. Por intermédio de sua filial, Servicios del Centro, teve participação minoritária (16,3\%) no consórcio Aguas Cordobesas, do qual adquiriu o controle acionário após a partida da companhia francesa Lyonnaise des Eaux em dezembro de 2006.

FONTE: elaborado a partir de informações extraídas de Lobina e Hall (2007).

\section{A trajetória da gestão privada do saneamento no Brasil}

No Brasil, a Lei Federal de Concessões, promulgada em fevereiro de 1995, no início do governo do presidente Fernando Henrique Cardoso (1995-2002), encerra uma longa tradição de monopólio público na prestação dos serviços de saneamento básico no país, que remonta à década de 30 do século passado, abrindo caminho para a participação de operadores privados neste setor. Quatro meses depois, o primeiro contrato de concessão de serviços de abastecimento de água e esgotamento sanitário à iniciativa privada do país é firmado na cidade de Limeira (SP). Com uma população de aproximadamente 250 mil habitantes, o município concedeu a gestão dos referidos serviços por 30 anos à companhia Águas de Limeira, formada pela associação de uma filial da Suez-Lyonnaise des Eaux com a construtora Odebrecht. Pouco depois, ainda em 1995, o município de Ribeirão Preto, cuja população atingia cerca de 550 mil habitantes, assinou um contrato B.O.T. (Build Operate and Transfer) com a empresa estadunidense CH2M Hill, a qual foi encarregada de construir e operar durante 20 anos duas estações de tratamento de esgotos. A gestão privada do saneamento no Estado de São Paulo vai se de- senvolver principalmente sob formas de delegação parcial, como esta, as quais, de acordo com a Associação Nacional dos Concessionários Privados de Saneamento (ABCON), envolviam 17 contratos contra apenas sete concessões plenas (i.e.: que contemplam o conjunto de atividades de abastecimento de água e esgotamento sanitário) em 2009.

As concessões privadas de saneamento se desenvolveram mais depressa e com maior alcance no Estado do Rio de Janeiro (cf. Tabela 2). Campos, com cerca de $400 \mathrm{mil}$ habitantes, foi a primeira cidade fluminense a firmar um contrato de concessão à iniciativa privada neste setor em 1996. Os serviços de água e esgotos do município foram concedidos por 30 anos à companhia Águas do Paraíba, formada por um consórcio nacional de empresas do grupo Águas do Brasil (cf. Quadro 2). No ano seguinte, Petrópolis, Niterói e três municípios da Região dos Lagos seguem o mesmo caminho, concedendo os respectivos serviços a empresas do mesmo grupo ${ }^{4}$. As firmas estrangeiras chegam ao mercado fluminense em 1998, quando cinco outros municípios da Região dos Lagos concedem por 25 anos os respectivos serviços de água e esgotos à companhia Prolagos, controlada pelo grupo Águas de Portugal ${ }^{5}$. No ano seguinte, é a vez de Nova Friburgo, cujos serviços em questão são concedidos à empresa Earth Tech, pertencente ao grupo Tyco, de capital estadunidense.

\footnotetext{
${ }^{4} \mathrm{O}$ último contrato é uma concessão multimunicipal em que os municípios (Araruama, Saquarema e Silva Jardim) compartilham a titularidade sobre o abastecimento de água com o Estado do Rio de Janeiro.

${ }^{5}$ Trata-se de contrato multimunicipal que envolve os municípios de Arraial do Cabo, Búzios, Cabo Frio, Iguaba Grande e São Pedro da Aldeia, semelhante ao firmado anteriormente na região.
} 
VARGAS, M. C.; GOUVELLO, B. de. Trajetória e perspectivas da gestão privada do saneamento...

TABELA2 - PRINCIPAIS CONTRATOS DE CONCESSÃO DOS SERVIÇOS DE ABASTECIMENTO DE ÁGUAE ESGOTAMENTO SANITÁRIO À INICIATIVA PRIVADA FIRMADOS NO BRASIL, A PARTIR DOS ANOS 1990, POR ORDEM CRONOLÓGICA

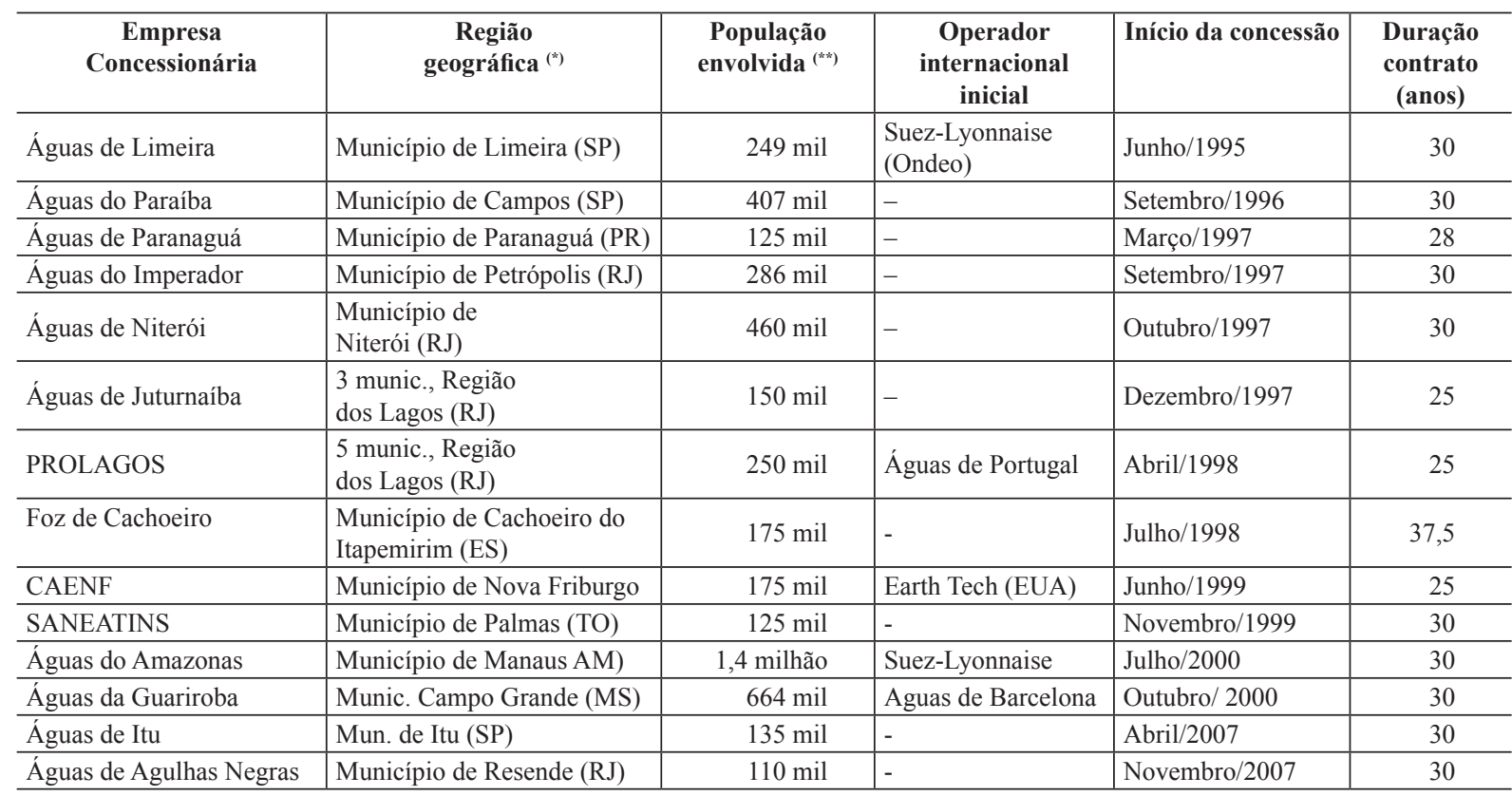

(*) Com exceção de Niterói, os contratos envolvem apenas a área urbana dos respectivos municípios.

${ }^{(* *)}$ População total sob responsabilidade do operador privado, dotada ou não de acesso aos serviços via redes públicas de água e esgotos, no ano 2000: números arredondados, extraídos do Censo 2000, IBGE.

Este primeiro movimento de expansão da gestão privada do saneamento se concentra em torno de pouco mais de uma quinzena de cidades da região sudeste, caracterizando-se por uma repartição desigual do mercado entre as empresas nacionais e as de capital estrangeiro, em favor das primeiras.

Porém, a perspectiva de privatização das poderosas Companhias Estaduais de Saneamento Básico (CESB), herança da política nacional de saneamento do regime militar, atrai fortemente o interesse das grandes corporações internacionais multisserviços. De fato, a privatização das CESB foi um dos principais objetivos da política setorial estabelecida para esta área no governo do presidente Cardoso, que chegou a impor a alguns Estados a venda de sua própria empresa neste setor como uma pré-condição para renegociação das respectivas dívidas junto à União. Neste contexto, em junho de 1998, o grupo Veolia comprou cerca de $40 \%$ do capital da SANEPAR, a companhia de saneamento do Estado do Paraná. O mesmo grupo também esteve presente na tentativa abortada de privatizar a CEDAE, companhia de saneamento do Estado do Rio de Janeiro. Mas, a exemplo do que iria se passar com outras companhias estaduais do setor que se pretendeu privatizar, a venda da CEDAE foi impedida por longas batalhas políticas e judiciais sobre a titularidade dos serviços (VARGAS, 2005).

Contudo, enquanto tais batalhas eram disputadas no cenário nacional, uma segunda onda de concessões dos serviços de saneamento básico a operadores privados desencadeou-se nas regiões menos desenvolvidas. Em 1998, três quartos das ações da SANEATINS, companhia de saneamento do Estado do Tocantins, foram vendidos a um grupo privado brasileiro, a EMSA, tornando-se a primeira concessionária estadual do setor cujo controle acionário foi transferido ao capital privado (cf. Quadro 2). Dois anos depois, um processo de "municipalização" progressiva do saneamento se iniciou no Estado do Mato Grosso, após a aprovação de uma lei autorizando a dissolução da concessionária estadual do setor. Este processo resultou na formação 
de alguns grupos privados locais que hoje estão à frente de numerosas concessões de saneamento em municípios de pequeno porte neste Estado.

As multinacionais também participam deste movimento de expansão da gestão privada do saneamento em direção às regiões menos desenvolvidas, conseguindo obter dois grandes contratos em 2000. Em julho deste ano, a empresa Águas do Amazonas, formada por um consórcio liderado pelo grupo Suez-Lyonnaise, venceu a concorrência pela concessão por 30 anos dos serviços de abastecimento de água e esgotamento sanitário de Manaus, cuja população já alcançava, na época, cerca de 1,4 milhão de habitantes. Pouco depois, em outubro, um contrato semelhante é firmado entre a Prefeitura de Campo Grande e a empresa Águas da Guariroba, formada por um consórcio liderado pela companhia espanhola Aguas de Barcelona. Em ambos os casos, foi preciso primeiro "remunicipalizar" os serviços de saneamento da capital antes de concedê-los à iniciativa privada (VARGAS, 2002).

Entretanto, a gestão privada do saneamento enfrentava, naquele momento, uma forte oposição de diversos atores sociais organizados. As associações nacionais que congregam os serviços municipais e as companhias estaduais do setor, a ASSEMAE e a AESBE, respectivamente, cujos interesses são ameaçados pelo avanço das concessões privadas, aliaram-se a sindicatos, associações de consumidores, entidades religiosas, movimentos sociais e lideranças políticas de esquerda para resistir com sucesso às numerosas tentativas de delegação da gestão dos serviços de abastecimento de água e/ou esgotamento sanitário a operadores privados. Reunidas numa rede militante, a Frente Nacional de Saneamento, criada em 1997, tais organizações vão se engajar em numerosas campanhas contra a "privatização" do setor e em favor de uma política setorial nacional baseada na gestão pública. A mobilização desta rede, que também se articula internacionalmente a outras organizações e redes sociais, consegue inviabilizar as enormes pressões do governo federal para que alguns Estados privatizassem a respectiva concessionária do setor.

Ora, a privatização das CESB dependia não apenas da adesão dos Estados, mas também dos municípios envolvidos, os quais são tradicionalmente reconhecidos no país como o poder concedente, titular dos serviços neste setor. Diante da fraca adesão dos Estados e da oposição da maior parte dos municípios implicados, o governo federal buscou contornar este obstáculo institucional à sua política setorial pró-mercado com o envio de um projeto de lei ao parlamento, protocolado sob o número 4.147 , propondo a transferência da titularidade dos serviços dos municípios para os Estados em todas as situações em que os primeiros fizessem parte de metrópoles ou aglomerações urbanas. Mas o tiro saiu pela culatra, pois a oposição a este projeto fortaleceu e unificou as forças que se opunham à política de saneamento do governo federal, cuja mobilização impediu a votação do mesmo em 2002, conduzindo o presidente Lula a retirá-lo do Congresso Nacional logo no início de seu governo. Porém, mesmo que a rejeição deste projeto tenha desencorajado os grandes grupos internacionais que já investiam no Brasil neste setor, não foi essa a principal razão para que começassem a deixar o país naquele momento, mas, antes, os resultados desfavoráveis das primeiras concessões, juntamente com uma conjuntura internacional desfavorável.

Depois de obterem grandes contratos de concessão nos países do hemisfério Sul ao longo dos anos 1990, as companhias transnacionais passaram a enfrentar dificuldades políticas e financeiras neste setor. Contratos já tinham sido rompidos ou estavam em situação litigiosa na Argentina, na Bolívia, na Indonésia (Jacarta), nas Filipinas (Manila) e na África do Sul. Neste contexto, elas decidem deixar os chamados mercados emergentes para concentrar seus investimentos nos países do leste europeu. Assim, em face de diversos problemas políticos e financeiros nas concessões de Limeira e Manaus (contratos sub judice, tarifas defasadas, necessidades de investimento infladas etc.), a Suez-Lyonnaise decidiu vender sua participação no capital das respectivas concessionárias aos acionistas brasileiros (cf. Quadro 2). Problemas semelhantes levaram a companhia Aguas de Barcelona a fazer o mesmo com sua participação no capital da concessionária de Campo Grande, que a Veolia vendesse suas ações na SANEPAR e a companhia Águas de Portugal a sua participação na Prolagos. Contudo, o fato de as grandes companhias transnacionais que investiam no setor terem deixado o Brasil no fim do governo Cardoso não acarretou o declínio da gestão privada do saneamento no país. Ao contrário, tal fato representou uma espécie de preparação do terreno para uma terceira onda de expansão desta, conforme se discute na última parte deste texto.

Assim, podemos dizer que a gestão privada do saneamento continua a se desenvolver no Brasil, onde avança lentamente, por um lado, por meio da abertura de novos mercados regionais e, por outro, mediante a diversificação das modalidades legais de gestão delegada da prestação de serviços públicos neste e noutros setores. 

MENTO SANITÁRIO NO BRASIL*

Fruto da aquisição da Suez Ambiental, antiga holding de um conjunto de empresas de prestação de serviços controladas pela transnacional francesa, o grupo Solvi está presente em 50 municípios brasileiros e três peruanos. Sua principal empresa na área de resíduos urbanos, a VEGA Engenharia Ambiental, assumiu o controle da companhia Águas do Amazonas, concessionária dos serviços de água e esgotos de Manaus.

As empresas da holding CIBE Participações, que pertencem aos grupos Bertin e Equipav, constroem obras de infraestrutura e administram concessões nas áreas de rodovias, energia e saneamento. Sua filial CIBE Saneamento está à frente de três concessões importantes no setor: a dos serviços de água e esgotos de Campo Grande (resultado da aquisição das ações da companhia Aguas de Barcelona); a que envolve os cinco municípios da Região dos Lagos atendidos pela empresa Prolagos (anteriormente sob controle do grupo Águas de Portugal); além daquela dos serviços de saneamento da cidade de Itu (SP).

Reunindo quatro empresas do ramo de engenharia e construção civil provenientes do Rio de Janeiro, o grupo Águas do Brasil controla as principais concessões de saneamento deste Estado: Niterói, Campos, Petrópolis, Araruama, Saquarema, Silva Jardim e Nova Friburgo, atendendo cerca de um milhão e meio de usuários.

Controlada pelo grupo EMSA, cujas atividades compreendem obras e serviços de infraestrutura concentradas nas regiões norte e centro-oeste, a SANEATINS é uma sociedade de economia mista cujo capital se reparte entre a EMSA (76\%) e o Governo do Estado do Tocantins (24\%). Criada em 1989 como uma empresa pública de direito privado, a SANEATINS teve seu controle acionário transferido ao setor privado em 1998. Atualmente, possui a concessão dos serviços de água e saneamento de 111 municípios no Tocantins e de outras cinco cidades no Estado do Pará, totalizando cerca de 1,2 milhão de usuários.

" Obs.: Elaborado pelos autores a partir de dados de julho de 2009 fornecidos pela ABCON, complementados por informações pesquisadas na internet.

\section{A dependência da trajetória das políticas nacionais de saneamento e as perspectivas da gestão privada nos dois países}

O desenvolvimento da gestão privada dos serviços de saneamento na Argentina e no Brasil, a partir dos anos 1990, apresenta fortes contrastes em termos de trajetória, de alcance e de perspectivas. Como explicar que políticas setoriais semelhantes, com a mesma orientação pró-mercado, adotadas mais ou menos na mesma época, por governos submetidos a pressões internas e externas comparáveis, tenham tido resultados tão diferentes nestes aspectos?

A abordagem evocada na primeira parte, inspirada na nova economia institucional, nos conduz a uma análise comparativa das políticas nacionais de saneamento implementadas no passado em cada país. Características específicas de tais políticas, e suas diferenças mútuas, parecem suficientemente estruturantes não apenas para explicar os contrastes observados na trajetória da gestão privada da água e do saneamento entre Argentina e Brasil, mas também para levantar as perspectivas atuais de evolução do setor em cada país.

\section{A presença do passado na evolução do setor nos dois paises}

Na década de 1990, quando Argentina e Brasil decidiram adotar políticas de saneamento pró-mercado, este setor, embora historicamente organizado sob modelos muito distintos, encontrava-se em crise nos dois países. Em ambos, a expansão da gestão privada foi pensada como uma estratégia para superar a crise vigente nas respectivas políticas setoriais nacionais. Porém, a celeridade e o alcance desigual da gestão privada nos dois países refletem diferenças na amplitude desta crise.

$\mathrm{Na}$ Argentina, a política nacional de saneamento havia sido estruturada em torno de uma grande empresa pública: Obras Sanitárias de la Nación (OSN). Criada em 1912 e subordinada ao Ministério de Obras Públicas, esta empresa foi encarregada da implantação das redes e da gestão dos serviços de abastecimento de água e esgotamento sanitário em praticamente todas as cidades do país. Este modelo centralizado, que funcionou de maneira satisfatória durante pouco mais de meio século, sofreu um lento colapso a partir de meados dos anos 1960, quando os outrora abundantes investimentos do governo central no 
setor começaram a ser drasticamente reduzidos diante da instabilidade macroeconômica e política do país. A gestão da empresa ressentia-se de deficiências administrativas e financeiras decorrentes, por um lado, da defasagem dos investimentos em relação à aceleração do crescimento urbano e, por outro, de uma cultura organizacional ineficiente, voltada para a implantação de infraestrutura e para a construção de obras subsidiadas. Neste contexto, no começo dos anos 1980, o governo central decidiu transferir a gestão dos serviços de saneamento de 161 municípios do interior do país que estavam sob administração da OSN aos respectivos governos provinciais, no âmbito de uma política de descentralização e austeridade fiscal apoiada pelo FMI e pelo Banco Mundial. Apenas os serviços de saneamento de Buenos Aires e 13 municípios vizinhos foram mantidos sob responsabilidade da companhia nacional, antes de sua privatização em 1993. A descentralização que precede a privatização deste setor na Argentina não se traduz em crescimento dos investimentos, nem tampouco melhorias na qualidade dos serviços, cujas taxas de atendimento e padrões de eficiência ficaram praticamente estagnados até o início dos anos 1990 (GOUVELLO, 2001).

No Brasil, a intervenção do governo federal na gestão dos serviços de saneamento básico ocorre tardiamente, uma vez que a administração deste setor tem sido tradicionalmente considerada de competência municipal. A implantação de uma verdadeira política nacional neste campo teve de esperar até o lançamento do Plano Nacional de Saneamento (PLANASA), no início dos anos 1970, em pleno regime militar. A política setorial embasada neste plano segue um modelo peculiar, que combina a centralização do planejamento, do financiamento e da política tarifária na esfera federal, sob o comando do Banco Nacional da Habitação (BNH), com a gestão descentralizada dos sistemas locais na órbita dos Estados, que assumem as funções executivas e operacionais desta política mediante a criação de concessionárias próprias de direito privado para administrar as concessões dos serviços municipais. Além das companhias estaduais, o modelo permite a participação indireta de empresas privadas de consultoria e engenharia na elaboração de estudos e projetos, na construção das obras e na prestação de serviços especializados.

Com a implantação do PLANASA e do sistema financeiro de saneamento administrado pelo BNH, o acesso dos municípios aos novos fundos federais e estaduais destinados ao setor passa a depender de sua prévia adesão à política federal, mediante a concessão dos respectivos serviços de água e/ou esgotos à concessionária do seu Estado. O processo envolvia a aprovação de uma lei de autorização na Câmara dos Vereadores e a assinatura de um contrato de concessão pela Prefeitura, por meio dos quais o município abandonava suas prerrogativas em relação ao setor, notadamente na questão das tarifas e seu reajuste. Carentes de investimentos na área, a maior parte dos municípios brasileiros aderiu ao PLANASA, de modo que as CESBs passaram a responder por aproximadamente três quartos da população urbana com acesso à água encanada em $70 \%$ das cidades brasileiras, além de mais da metade dos domicílios conectados à rede de esgotos. Porém, a recessão dos anos 1980 e o endividamento crescente destas empresas, cuja gestão foi geralmente marcada pelo clientelismo e por falta de transparência, conduziram ao desmoronamento do sistema financeiro de saneamento e à liquidação do BNH em 1986 (VARGAS, 1996).

Mas, contrariamente ao que se passou com o modelo OSN na Argentina, o desmantelamento do PLANASA não foi completo e não resultou numa crise generalizada do setor. Com efeito, os pilares centrais da política setorial nacional foram mantidos praticamente intactos: o FGTS continua sendo a principal fonte de financiamento do setor; a política tarifária permanece baseada em tarifas progressivas, associadas a subsídios cruzados; muitos contratos de concessão da época foram renovados e continuam em vigor; por fim, a participação das CESBs no setor continua amplamente predominante. Cabe lembrar que tais concessionárias se reuniram numa associação nacional, a AESBE, criada em 1985 para defender os interesses destas empresas junto ao parlamento e ao governo federal. Por outro lado, a desestruturação do PLANASA e o fim do regime militar permitiram que os municípios que permaneceram na gestão direta dos respectivos serviços de saneamento - igualmente organizados em torno de uma associação nacional, criada em 1984, a ASSEMAE - passassem a ter os mesmos direitos de acesso aos fundos federais destinados ao setor.

Diante da crise do modelo PLANASA, ambas as associações se mobilizaram ao lado de outras entidades representativas das empresas de capital privado associadas a este ramo de atividade (construtoras, firmas de engenharia, fornecedores de materiais etc.), visando debater e propor a formulação de uma nova política nacional de saneamento, o que favoreceu o desenvolvimento da cultura técnica e a acumulação de capital social no setor. A forte resistência que se opôs à política setorial pró-mercado proposta pelo presidente Cardoso derivou em grande parte da presença 
acentuada destes dois elementos no meio profissional do saneamento brasileiro, como uma herança derivada do antigo PLANASA, que não tem paralelo no modelo OSN (cf. Tabela 3).

TABELA 3 - COMPARAÇÃO ENTRE OS MODELOS OSN E PLANASA DE POLÍTICA SETORIAL

\begin{tabular}{l|c|l}
\hline Organização funcional & Argentina & Brasil \\
\hline Planejamento setorial & $\begin{array}{c}\text { Min. de Obras } \\
\text { Públicas }\end{array}$ & BNH \\
\hline Preparação de projetos & OSN & Firmas particulares \\
\hline Execução de obras & OSN & Firmas particulares \\
\hline $\begin{array}{l}\text { Administração, operação } \\
\text { e manutenção }\end{array}$ & OSN & $\begin{array}{l}\text { Companhias estaduais } \\
\text { de direito privado }\end{array}$ \\
\hline
\end{tabular}

FONTE: Elaborado pelos autores

A forte acumulação prévia de capital social no setor não foi o único mecanismo a frear o desenvolvimento da gestão privada do saneamento no Brasil. Outro, igualmente importante, deriva da força particular do município no federalismo brasileiro, que não tem paralelo no regime federativo argentino. O princípio da autonomia municipal, em boa parte preservado durante o regime militar, mesmo sob vigência do PLANASA, foi reforçado na Constituição Federal promulgada em 1988, que atribuiu aos municípios o mesmo status de entidades constitutivas da Federação que sempre tiveram os Estados. Além disso, a carta magna do Brasil reconhece o município como titular e poder concedente dos serviços de interesse local, categoria na qual costumam ser enquadradas as atividades de saneamento básico. O forte apoio dado a este princípio pela maior parte dos agentes do setor tornou-se uma espécie de barreira institucional à privatização das companhias estaduais de saneamento.

Tendo visto como as características do período anterior influenciaram o alcance das políticas de saneamento pró-mercado adotadas na Argentina e no Brasil ao longo dos anos 1990, resta-nos agora examinar o legado e as perspectivas de evolução da gestão privada dos serviços deste setor em ambos os países.

\section{A gestão privada do saneamento na Argentina e no} Brasil: legado e perspectivas

Partindo de trajetórias bastante distintas, ligadas a escolhas político-institucionais do passado, as tendências atuais de desenvolvimento da gestão privada dos serviços deste setor nos dois países apresentam não apenas divergências, mas também alguns pontos de convergência, herdados da fase neoliberal que prevaleceu na década de 1990 .

No que tange ao seu alcance, parece que as diferenças de trajetória da gestão privada do saneamento na Argentina e no Brasil se projetam no futuro. Se os conflitos acirrados entre as empresas concessionárias e as autoridades concedentes resultaram na ruptura dos contratos mais importantes na Argentina, o mesmo não ocorreu no Brasil, de onde as multinacionais partiram devido a uma reorientação na sua estratégia de investimentos no mercado internacional, já que a forte mobilização social contra as políticas de saneamento pró-mercado jamais desembocou na rescisão litigiosa ou pactuada de qualquer contrato. Por isso, a permanência de grupos privados nacionais em certas regiões da Argentina parece incerta, como a retomada dos serviços concedidos pela província de Salta, em maio de 2009, parece demonstrar; o declínio ou a estagnação da gestão privada do saneamento é a tendência setorial mais provável neste país.

Inversamente, a gestão privada deste setor continua a avançar no Brasil. Depois das dificuldades encontradas entre o fim do governo do presidente Cardoso e o início do governo Lula, esta tendência se desenvolve em diversas direções. Caracteriza-se, de um lado, pela emergência de novos grupos privados nacionais e novas modalidades de delegação da prestação dos serviços, nas quais os primeiros frequentemente se associam a empresas estrangeiras recém-chegadas no país, como a portuguesa AGS ou a espanhola OHL. Assim, ao lado de várias concessões espalhadas nos Estados de Mato Grosso e Tocantins e de algumas novas concessões importantes no Sudeste em 2007 (Itu, Resende), vemos surgir grandes contratos de delegação parcial dos serviços à iniciativa privada, sob novos arranjos institucionais, em metrópoles como São Paulo e Salvador ${ }^{6}$. Esta

\footnotetext{
${ }^{6}$ São as novas formas de parceria público-privada, criadas pela lei federal n 11.079/04: "concessão administrativa" e "concessão patrocinada". A primeira oferece garantias à empresa privada contratada para construir, operar e manter equipamentos por conta de uma companhia ou órgão público. A segunda permite ao concessionário privado receber, ao lado da receita tarifária, uma remuneração suplementar do poder concedente a título de participação nos investimentos e/ou garantia de rentabilidade do contrato.
} 
diversificação das modalidades legais de gestão privada, ausente na Argentina, é fruto de processos específicos, derivados de um legado comum do período neoliberal: a aceitação social da regulação como uma atividade técnica especializada.

A ideia da regulação como atividade especializada de entidade independente do operador e não subordinada à autoridade governamental aparece na Argentina e no Brasil durante os anos 1990, juntamente com o movimento de reforma do Estado e a privatização dos serviços públicos. Com o retorno da gestão pública no primeiro país, houve uma tendência a acreditar que a regulação não seria mais necessária. Mas, o debate sobre a oportunidade de conservar as entidades reguladoras independentes terminou por consagrar a ideia de que se trata de uma medida justificada do ponto de vista conceitual e à luz da experiência internacional. Em ambos os países, a regulação permitiu desenvolver as noções de tarifa social, contabilidade regulatória e benchmarking, as quais não são mais contestadas. Mas, para além da aplicação destes princípios gerais, a regulação do setor não foi consolidada em um marco regulatório mais amplo na Argentina, como ocorreu no Brasil. Ao contrário, os órgãos reguladores tiveram seus meios e poderes amplamente enfraquecidos no primeiro país, devido à perda de importância relativa das tarifas no financiamento dos serviços em relação aos recursos do orçamento público. Inversamente, tais organismos tiveram seu poder e seus meios ampliados no Brasil por conta da nova legislação federal que estabelece os princípios da política nacional de saneamento, entre os quais o da regulação independente como condição de validade dos contratos de delegação. Coroada pela lei federal 11.445, de 2007, esta legislação é fruto de um compromisso entre os principais agentes implicados na gestão do setor (municípios, concessionárias estaduais, empresas privadas e movimentos sociais) e exprime uma capacidade de negociação e cooperação que deriva da acumulação de capital social neste setor.

Enfim, a gestão privada favoreceu uma reafirmação progressiva do papel dos atores locais, além de uma demanda crescente por transparência e participação dos usuários no processo de decisão e regulação do setor em ambos os países. Na Argentina, a participação dos municípios nas decisões relativas à expansão dos serviços cresceu, tornando-se nitidamente mais importante hoje do que na época da OSN. O mesmo ocorreu no Brasil, onde o novo quadro institucional do setor reforça consideravelmente as prerrogativas dos municípios enquanto poder concedente face aos tempos do PLANASA, independentemente do estatuto jurídico do operador ou do tipo de contrato em questão. Por fim, os movimentos sociais e as associações de usuários, fortalecidos nos dois países durante o período neoliberal, vêm ganhando importância desde então, com novas instâncias de participação na gestão do setor (audiências públicas, representação em conselhos etc.).

\section{Conclusã̃o}

Em 2010, a presença da empresa privada na prestação dos serviços urbanos de água e esgotos tornou-se comparável na Argentina e no Brasil, onde atendem entre 10 e $15 \%$ dos usuários do setor. Porém, no que tange às perspectivas de evolução da gestão privada, esta "convergência conjuntural" revela-se bastante diferente. Na Argentina, a implantação de uma política de saneamento pró-mercado foi brutal e instável, não havendo qualquer tipo de composição com o modelo centralizado anterior. No Brasil, sua adoção foi mais lenta e cautelosa, buscando articulações com características persistentes do modelo anterior, o que permitiu a absorção progressiva dos novos parâmetros de organização setorial pelo sistema de atores egressos do antigo modelo.

Mesmo não sendo mais vista como a panaceia para os problemas dos países em desenvolvimento neste setor, a gestão privada do saneamento deixa um legado de princípios que vai além deste modelo de prestação dos serviços. Por outro lado, as dificuldades encontradas nas experiências mais longas fizeram emergir maior grau de realismo e hierarquização de objetivos na revisão de contratos excessivamente ambiciosos. No contexto da reafirmação do papel das autoridades locais e de uma maior abertura à participação social, tais experiências favoreceram o surgimento de soluções pragmáticas mais adequadas às necessidades e possibilidades locais. 


\section{Referências}

AZPIAZU, D. et al. Agua y energía: mapa de situación y problemáticas regulatorias de los servicios públicos en el interior del país. Buenos Aires: FLACSO, 2008. 190 p.

BOTTON, S. (Coord.). Les multinationales et les marchés du sud. Pourquoi Suez a-t-elle quitté Buenos Aires et La Paz? Paris: GRET, 2007. (Col. Débats \& Controverses, n. 1).

BREUIL, L. Renouveler le partenariat public-privé pour les services d'eau dans les pays en développement. Tese (Doutorado) - ENGREF/GEA. 321 p. Paris, 2004.

CASTRO, J. E. Agua y governabilidad: entre la ideología neoliberal y la memoria histórica. Cuadernos del Cendes, año 22, n. 59, Tercera Epoca, p. 1-21, mayo-agosto 2005.

COING, H. "Revenir à la régie"... ou inventer de nouvelles formes de gestion publique et collective? L'expérience latino-américaine. La Pensée, n. 348, p. 49-56, octobre-décembre 2006.

DUCCI, J. Salida de operadores privados internacionales de agua en América Latina. Washington D.C.: BID, 2007. 172 p.

DUPRÉ-ECHEVERRIA, E. Changements institutionnels dans le secteur de l'eau et de l'assainissement au Chili. In: SCHNEIER, G.; GOUVELlO, B. (Dir.). Eaux et réseaux: les défis de la mondialisation. Paris: IHEAL, p. 311-319, 2003.

FOSTER, V. Ten Years of Water Service Reform in Latin America: Toward an Anglo-French Model. The World Bank Group, 2005.

GÓMEZ-LOBO, A.; VARGAS, M. La regulación de las empresas sanitarias en Chile: una revisión crítica. Perspectivas, v. 6, n. 1, p. 79-109, 2002.

GOUVELLO, B. de. Les services d'eau et d'assainissement en Argentine à l'heure néolibérale. La mondialisation des "modèles” à l'épreuve du territoire, Paris: L'Harmattan, 2001. 240 p.

; LENTINI, E.; SCHNEIER-MADANES, G. Que reste-t-il de la gestion privée de l'eau en Argentine? Retour sur l'échec des délégations à des consortiuns internationaux. In: SCHNEIER-MADANES G. (Dir.). L'eau Mondialisée. Paris: La Découverte, 2010.

GUASCH, J. L. Granting and renegotiating infrastructure concessions. Doing it right? World Bank Institute, Development Studies, 2004.
JAGLIN, S. Services d'eau en Afrique subsaharienne. Paris: CNRS Éditions, 2005.

LOBINA, E.; HALL, D. Water privatisation and restructuring in Latin America. PSIRU, Business School, University of Greenwich, 2007. 60 p.

MAYAUX, P.-L. Retour sur le retrait de Suez de La Paz-El Alto. Flux, n. 74, p. 83-91, 2008.

NORTH, D. C. Institutions, institutional change and economic performance. Cambridge: Cambridge University Press, 1990.

PUTNAM, R. D. Making Democracy Work: Civic traditions in modern Italy. Princeton: New Jersey University Press, 1993.

ROBLES, R. R.; VIGNOLI, F. H. et al. Verification of the Private Sector's Participation in Providing Water Supply and Sanitary Sewage Services in Brazil. Relatório preparado pelo INECON e pela Fundação Getúlio Vargas para a Secretaria Nacional de Saneamento do Ministério das Cidades, no âmbito do projeto "Water Dialogues". São Paulo, outubro de 2008.

SCHNEIER, G.; GOUVELLO, B. (Dir.). Eaux et réseaux: les défis de la mondialisation. Paris: IHEAL, 2003. (Coll. Travaux et Mémoires, n. 76).

SEPPÄLÄ, O. T. International and national policies that facilitate or hinder private participation in Water and Sanitation Services, especially in developing countries. Projet PRINWASS, Relatório de Pesquisa D2. Oxford, 2003. 106 p.

VARGAS, M. C. Gestion municipale versus gestion étatique des services d'eau et d'assainissement dans la région metropolitaine de São Paulo: acteurs, territoires et régulation. Tese (Doutorado em Urbanismo) - LATTS/IUP, Universidade de Paris Val de Marne. Paris, 1996.

Desafios da transição para o mercado regulado no setor de saneamento. Anuário 2002 GEDIM, Rio de Janeiro: Lumen Juris, p. 113-158, 2002.

O negócio da água. Riscos e oportunidades das concessões de saneamento à iniciativa privada. São Paulo: Annablume, 2005. 